\title{
Ichthyology 50 years in Japan-Celebrating its history to set the stage for the next generations
}

\author{
Symposium abstracts
}

C The Ichthyological Society of Japan 2018

\section{History of the Ichthyological Society of Japan-its establishment and development}

\author{
Seishi Kimura \\ Fisheries Research Laboratory, Mie University, 4190-172 \\ Wagu, Shima-cho, Shima, Mie 517-0703, Japan. \\ E-mail: kimura-s@bio.mie-u.ac.jp
}

The Ichthyological Society of Japan (ISJ) was established on 3 April 1968 and celebrated 50 years of existence in 2018. The significance of this first commemorative project is primarily aimed to record the history of the ISJ, in addition to expressing the hope for future smooth management and development of the society.

Twenty-two years prior to the establishment of ISJ, the "Uo no Kai" (Japanese Society of Ichthyology) was formed in 1946, catering to people interested in fish biology. From 1950, "Uo no Kai" edited the old "Japanese Journal of Ichthyology" (JJI) (Vols. 1-14), published as an academic magazine. However, the number of manuscripts submitted to the journal progressively decreased, although many ichthyologists hoped for a revival of its fortunes. Renewed impetus followed the visit of many foreign ichthyologists to Japan for the 11th Pacific Science Association Conference, held in Tokyo in 1966. From this was born the idea of establishing ISJ. In 1967, some members of "Uo no Kai" began planning for the establishment of a new academic society related to fish biology, advancing various administrative procedures. Finally, ISJ was founded in 1968.

The important activities of ISJ have always focused on periodic publication of an academic journal(s) and Annual Meetings, accompanied by a symposium(a). The new JJI (Vols. 15-41) has subsequently published four issues per volume. Over that time, JJI steadily strengthened its academic standing, increasing the proportion of Englishlanguage papers year by year, and achieving an international reputation as an academic journal of fish biology in the IndoPacific region. However, during this time, the proportion of Japanese-language papers decreased significantly. Accordingly, Ichthyological Research (IR) (published quarterly in English) and JJI (semi-annually in Japanese with English abstracts) have been issued since 1996 (Vols. 42-). From 2001, IR has been published by Springer Verlag, Tokyo (now Springer Japan), for greater internationalization and reduction in publishing costs.

The first annual meeting with research presentations was held in March 1969, in Tokyo. Such meetings continued each spring in Tokyo until 1995, venues being the National Science Museum, Tokyo (now National Museum of Nature and Science), or Tokyo University of Fisheries (now Tokyo University of Marine Science and Technology). Since 1996, the annual meetings have been held in autumn each year, rotating between different venues in Japan. Symposia held in conjunction with the annual meeting have continued from 1973. "Autumn Symposia" started in 1972 and continued until 1977.

The ISJ committee initially included only the Board of Editors. The society has since grown to include the Nature Conservation Committee, Japanese Standard Name Committee, Electronic Information Committee, Gender Equality Committee, History Committee and Awards Committee, in addition to the Board of Editors

ISJ members initially numbered ca. 330; 50 years later, membership reached 1101 individuals (April 2018). The number of papers published in JJI for Vol. 15 (1968-1969) was only 14, compared with 75 in JJI+IR for Vol. 64 (2017). Although society membership has remained relatively flat (or gradually decreasing) in recent years, the number of articles published has increased remarkably. 


\section{Historical perspective of ichthyology in Japan}

\section{Keiichi Matsuura}

\section{National Museum of Nature and Science, Tsukuba, Ibaraki 305-0005, Japan. \\ E-mail:matsuura@kahaku.go.jp}

The Japanese Archipelago extends for 3,000 km from north to south, being almost equal in length to the east coast of Australia. The northeastern coast of Hokkaido, located at the northernmost part of the archipelago, is covered with ice in winter, whereas the southernmost region, the Ryukyu Islands, has well-developed coral reefs. Between these two extremes, there exist various aquatic habitats: sandy beaches, mud flats, estuaries, rocky reefs, kelp beds and very deep trenches, exceeding $8,000 \mathrm{~m}$ in depth, in the marine realm, in addition to freshwater rivers, lakes, ponds and marshes. These greatly diversified aquatic habitats have resulted in one of the richest fish faunas in the world, totaling some 4300 species, $13 \%$ of fish species worldwide. Such diversification of fishes has attracted western naturalists since the 18 th century, including Maarten Houttuyn and Carl L. Thunberg. Although both described some Japanese fishes as new to science, Philipp F. B. von Siebold was the first to make extensive collections, taking large numbers of animal and plant specimens back to the Netherlands. Based on fishes collected by Siebold, Coenraad J. Temminck and Hermann Schlegel described many fishes in Fauna Japonica from 1843 to 1850 .

After the Meiji Restoration in 1868, Japanese naturalists began studying the systematics of Japanese fishes. In the early 1900s, the American ichthyologist David S. Jordan visited Japan to collect fishes, taking them back to the USA. He and his colleagues, including Shigeho Tanaka, studied the taxonomy and zoogeography of these fishes, resulting in numerous publications, including many new species. Although Japanese ichthyologists were influenced by Jordan and his colleagues before World War II, Shigeho Tanaka, Yaichiro Okada and Kiyomatsu Matsubara developed their own ichthyological studies on fishes of Japan and adjacent areas. During the war, many universities and research institutions in Japan were severely damaged, resulting in difficult times for the Japanese ichthyological community. However, Matsubara and his students subsequently developed an ichthyological center at the Kyoto University, resulting in many papers on the taxonomy and phylogeny of various groups of fishes being published from the 1950s to the early 1970s.

The Ichthyological Society of Japan, established in April 1968, further stimulated Japanese ichthyologists to develop their studies on various aspects of ichthyology.
Over subsequent years, about 10 new fish species have been described annually by Japanese ichthyologists, one of the highest numbers of new fish species described by researchers in a single country and an indication of the great contribution of Japanese ichthyologists to worldwide understanding of fish diversity. From the 1980s, the phylogenetic relationships of many fish groups have been determined on the basis of comparative morphology, although DNA analyses have become progressively more sophisticated, helping to clarify the phylogenetic relationships of many fish groups in recent years. Although Japanese ichthyologists are still occupying many research positions in universities, museums and other institutions in Japan, significant reductions in the number of fish researchers, especially taxonomists, have occurred in other developed world regions, including Europe, USA, Canada, Australia and New Zealand. This underlines the importance of Japanese ichthyologists continuing to play leading roles in systematic studies on fishes.

\section{Perspectives on deep-sea fish taxonomy: current progress, issues and future initiatives}

\section{Naohide Nakayama}

\section{School of Marine Science and Technology, Tokai University, Shimizu, Shizuoka 424-8610, Japan. \\ E-mail: gadiformes@gmail.com}

Occupying more than $90 \%$ of the total volume of the world's oceans, the deep sea is by far the largest habitat for fishes. However, the taxonomic inventory of deep-sea fishes is still far from complete, due both to the limited number of taxonomic experts and limited collecting effort for this vast area compared with well-investigated freshwater and costal habitats (Mora et al. 2008; Eschmeyer et al. 2010; Webb et al. 2010). Recent studies have estimated that about 21-30 $\%$ of marine fish species are still to be undescribed, many of which likely occupy deep-sea habitats (Mora et al. 2008; Eschmeyer et al. 2010). Accordingly, further taxonomic studies of deep-sea fishes are strongly encouraged for elucidation of global fish species diversity.

Grenadiers (family Macrouridae) comprise the largest group within the order Gadiformes, including more than 360 named species in ca. 28 genera, with many other species still to be described (Iwamoto 2008; Nelson et al. 2016; Nakayama pers. observ.). As part of a project to revise the global diversity of grenadiers, we have conducted a taxonomic review of Japanese species over the last 10 years. Although the taxonomy of Japanese grenadiers has been progressively reviewed over the years, by Jordan and Starks in Jordan and Snyder (1904), Gilbert 
and Hubbs (1918) and Okamura (1970a, b), a number of additional specimens have accumulated in various museum collections as a result of collecting efforts in previously unexplored areas. In addition, several issues regarding the synonymies of nominal taxa have made identification of common species difficult. Our study, based on examinations of museum specimens, complemented by field surveys, resulted in the recognition of 71 species in 15 genera of grenadiers from Japanese waters, including at least six undescribed species at the time of examination (three subsequently described: Coryphaenoides soyoae Nakayama and Endo 2016; Hymenocephalus yamasakiorum Nakayama, Endo and Schwarzhans 2015; Nezumia shinoharai Nakayama and Endo 2012) and three new records (Coelorinchus sheni Chiou, Shao and Iwamoto 2004; Coryphaenoides rudis Günther 1878; Odontomacrurus murrayi Norman 1936). In addition, seven nominal species, previously considered valid, were recognized as junior synonyms of other nominal species. These discoveries highlighted how little we know about the diversity of deep-sea fishes, even in previously well-studied taxa and regions.

Recent developments in molecular biology have enabled verification of the validity of morphology-based species discrimination from a different perspective, by using DNA barcoding (e.g., Hebert et al. 2003). In our study of Japanese grenadiers, DNA barcoding also identified boundaries between morphologically closely similar species. Furthermore, barcoding may also help to identify unknown samples to a particular species (e.g., Ratnasingham and Hebert 2007), and will become an important tool for species identification for biologists unfamiliar with taxonomy. However, it should be emphasized that accuracy of morphological species identification of voucher specimens is crucial to subsequent molecular analyses. Therefore, the role of morphology-based taxonomy will become no less important in the DNA barcoding era.

This presentation gives our perspectives on problems and points in the practice of deep-sea fish taxonomy, citing our recent results for Japanese grenadiers. The advantages, limitations and expected roles of morphology-based taxonomy and DNA barcoding are also discussed.

\section{References}

Eschmeyer WN, Fricke R, Fong JD, Polack DA (2010) Marine fish diversity: history of knowledge and discovery (Pisces). Zootaxa 2525: 19-50

Gilbert CH, Hubbs CL (1916) Report on the Japanese macrourid fishes collected by the United States fisheries steamer "Albatross" in 1906, with a synopsis of the genera. Proc US Natl Mus 51: 135214 , pls $8-11$
Hebert PDN, Cywinska A, Ball, SL, deWaard JR (2003) Biological Identifications through DNA barcodes. Proc R Soc Lond B 270: 313-321

Iwamoto T (2008) A brief taxonomic history of grenadiers. In Orlov AM, Iwamoto T (eds) Grenadiers of the world oceans: biology, stock assessment, and fisheries. American Fisheries Society, Bethesda, pp 3-13

Jordan DS, Starks EC (1904) List of fishes dredged by the steamer Albatross off the coast of Japan in the summer of 1900, with descriptions of new species and a review of the Japanese Macrouridae. Bull US Fish Comm 22: 577-630, pls 1-8

Mora C, Tittensor DP, Myers R (2008) The completeness of taxonomic inventories for describing the global diversity and distribution of marine fishes. Proc R Soc B 275: 149-155

Nelson JS, Grande TC, Wilson MVH (2016) Fishes of the world, fifth edn. John Wiley \& Sons, Inc., Hoboken

Okamura O (1970a) Fauna Japonica, Macrourina (Pisces). Academic Press of Japan, Tokyo

Okamura O (1970b) Studies on the macrouroid fishes of Japan: Morphology, ecology and phylogeny. Rep Usa Mar Biol Sta 17: 1-179

Ratnasingham S, Hebert PDN (2007) BOLD: The Barcode of Life Data System (www.barcodinglife.org). Mol Ecol Notes 7: 355-364

Webb TJ, Berghe EV, O’Dor R (2010) Biodiversity's big wet secret: the global distribution of marine biological records reveals chronic under-exploration of the deep pelagic ocean. PLoS ONE 5: e10223. https://doi.org/10.1371/journal.pone.0010223

\section{Species tree vs. gene tree: species problems in Japanese fishes}

\section{Yoshiaki Kai}

\author{
Field Science Education and Research Center, Kyoto \\ University, Maizuru, Kyoto 625-0086, Japan. \\ E-mail: mebaru@kais.kyoto-u.ac.jp
}

The species category is a fundamental unit in biology, being important for fisheries management and conservation of endangered species, especially fishes. More than 30 criteria for species concepts are known (Zachos 2016), with the "Biological Species Concept", based on reproductive isolation, having been generally applied for delimiting fish species. However, fish species delimitation is readily inferable on the basis of morphological divergence due to the difficulty in directly observing reproductive isolation. In cases of allopatric taxa, the objective inference of reproductive potential is difficult and requires the use of many different sources of data, including molecular, morphological and ecological data (Fujita et al. 2012). However, morphological characters may often be subject to convergent evolution as they are under similar selective pressure (Fišer et al. 2018), resulting in discordance between a morphologically defined species tree and a gene tree. Conversely, genotype-phenotype discordance can provide insights for the detection of convergent evolution.

The Sea of Japan, a marginal sea in the western North Pacific, is continuous with neighboring water bodies via 
shallow narrow straits, but is considered to have been almost completely isolated from them on a number of occasions during glacial periods. Past geographic isolation of the Sea of Japan has played an important speciation role, and recent molecular phylogenetic studies having demonstrated a number of geographically significant sister relationships. For example, snailfishes of the Careproctus rastrinus species complex, widely known from the North Pacific, have been revealed as including nine genetically divergent groups, most of which corresponded well with the Sea of Japan and other marginal seas in the North Pacific (Kai et al. 2011). These groups are also morphologically different and are now recognized as distinct species (Orr et al. 2015). In contrast, no genetic divergence was found between two morphologically different psychrolutids, Malacocottus gibber, known from the Sea of Japan, and Malacocottus zonurus, known from the Sea of Okhotsk, Bering Sea and Pacific Ocean (Adachi et al. 2009; Stevenson 2015). This evidence suggests that the level of genetic divergence among sister species (populations within a species) in the Sea of Japan and neighboring waters are not always consistent with morphological divergence.

Using the Barcode of Life Data System (BOLD), the levels of genetic divergence among sister species (populations) in the Sea of Japan and neighboring water bodies are herein reviewed, with special focus on the bottom-dwelling fishes in Cottoidei and Zoarcoidei. The analyses showed that the levels ranged variously and were continuous among taxa, suggesting difficulty in species delimitation on the basis of continuous variables. Interestingly, some sister species, recognized on the basis of clear morphological differences, exhibited no genetic divergence. In contrast, some regional populations within a species exhibited rather clear morphological (and low level genetic) divergence. In most cases, the species (or populations) in the Sea of Japan are characterized as having a larger eye, larger mouth and lower counts of meristic characters than the species (or populations) in neighboring waters. Because the deeper area of the Sea of Japan is uniquely characterized by poor species diversity and low water temperature, compared with neighboring water bodies (Gamo et al. 2014; Shinohara et al. 2014), such morphological differences may suggest that the species (or populations) in the Sea of Japan may be subject to regional adaptation.

\section{References}

Adachi T, Hagihara S, Itoh M, Shinohara G, Hayashi I, Kojima S (2009) Genetic population structure and morphological characters of Japanese psychrolutids of genus Malacocottus (Scorpaeniformes: Psychrolutidae). Ichthyol Res 56: 323-329

Fišer C, Robinson CT, Malard F (2018) Cryptic species as a window into the paradigm shift of the species concept. Mol Ecol 27: $613-635$
Fujita MK, Leaché AD, Burbrink FT, McGuire JA, Moritz C (2012) Coalescent-based species delimitation in an integrative taxonomy. Trend Ecol Evol 27: 480-488

Gamo T, Nakayama N, Takahata N, Sano Y, Zhang J, Yamazaki E, Taniyasu S, Yamashita N (2014) The Sea of Japan and its unique chemistry revealed by time-series observations over the last 30 years. Monogr Environ Earth Planets 2: 1-22

Kai Y, Orr JW, Sakai K, Nakabo T (2011) Genetic and morphological evidence for cryptic diversity in the Careproctus rastrinus species complex (Liparidae) of the North Pacific. Ichthyol Res 58: $143-154$

Orr JW, Kai Y, Nakabo T (2015) Snailfishes of the Careproctus rastrinus complex (Liparidae): redescriptions of seven species in the North Pacific Ocean region, with the description of a new species from the Beaufort Sea. Zootaxa 4018:301-348

Shinohara G, Nakae M, Ueda Y, Kojima S, Matsuura K (2014) Annotated checklist of deep-sea fishes of the Sea of Japan. Natl Mus Natr Sci Monog 44: 225-291

Stevenson DE (2015) The validity of nominal species of Malacocottus (Teleostei: Cottiformes: Psychrolutidae) known from the eastern North Pacific with a key to the species. Copeia 2015: 22-33

Zachos FE (2016) Species Concepts in Biology. Springer International Publishing, Switzerland

\section{The Japanese Archipelago as an evolutionary laboratory: genomics of hybrid fish populations}

\section{Shotaro Hirase}

Fisheries Laboratory, Graduate School of Agricultural and Life Sciences, The University of Tokyo, Hamamatsu, Shizuoka 431-0214, Japan.

E-mail: ashirase@mail.ecc.u-tokyo.ac.jp

Speciation occurs when one population separates into two which are reproductively isolated; hybridization between these populations is recognized as a process that prevents speciation (Dobzhansky 1951). Recently, however, hybridization between divergent populations has been recognized as a powerful speciation mechanism and a driving force in generating biodiversity (Abbott et al. 2013). Homoploid Hybrid Speciation (HHS) is a process by which a novel reproductively isolated group arises through hybridization of parental genomes, but without changes in the chromosome number. Its importance has recently received more attention because of the large number of examples found by empirical studies (Schumer et al. 2014). To understand the evolutionary process, genomic features of homoploid hybrid species were investigated, their genomes being expected to include secondary evolutionary changes after HSS, which may obscure essential processes for generating novel hybrid groups (Nolte and Tautz 2010).

Population genomics of a hybrid zone between divergent groups can play an important role in elucidating the first steps toward a homoploid hybrid species (Nolte and 
Tautz 2010). To date, we have studied hybrid populations of Pacific Ocean (PO) and Japan Sea (JS) groups in two coastal Japanese gobies, Chaenogobius annularis and Leucopsarion petersii (see Kokita and Nohara 2011; Hirase and Ikeda 2014; Hirase et al. 2016). The genomic status of a hybrid population of $C$. annularis on the Sanriku coast (Hirase et al. 2015) was analysed by de novo genome sequencing, RADseq, exome sequencing, and whole mitochondrial genome (mitogenome) sequencing. Although all hybrids had the genomes of both groups in a ratio of approximately $50 \%$, they also showed excess ancestry of either group in many genomic regions, suggesting a mosaic feature of hybrid genomes. In addition, significantly large numbers of nonsynonymous substitutions occurred in mitogenomes in the hybrid population, such substitutions having been likely caused by mismatch combinations with nuclear mitochondria-related genes, i.e. mitonuclear incompatibility (Burton and Barreto 2012). These results suggested that novel genomic combinations following hybridization promoted novel mitogenome mutations.

The two groups of L. petersii were genetically and phenotypically divergent, with the JS group having greater body size and vertebral numbers (Kokita and Nohara 2011). Hybridization was found in two regions, the Seto Inland Sea and the Joban-Kashimanada, characterized by different environments (Kokita and Nohara 2011). Examinations of multiple hybrid populations are important for assessing whether the consequences of hybridization vary with environmental conditions (Morgan-Richards and Wallis 2003). Accordingly, we performed integrated analyses of genotype and phenotype data for these hybrid populations. RAD-seq data showed that Seto Inland Sea hybrid populations were genetically close to the JS group and Joban-Kashimanada hybrid populations to the $\mathrm{PO}$ group. Phenotypic patterns of vertebral number were clearly explained by genotypes, but those of body size were not in the two hybrid zones. These findings demonstrated that hybridization could lead to variable genomic and phenotypic consequences under different environmental settings.

Phylogeographic studies have demonstrated deep genetic divergence and hybridization in Japanese fishes, enabling our understanding of evolution by hybridization at the genome level for non-model species. I am hopeful that population genomics of Japanese fishes in hybrid zones, termed "Natural Laboratory" (Hewitt 1988), will provide novel insights into biological evolution.

\section{References}

Abbott R, Albach D, Ansell S, Arntzen JW, Baird SJ, Bierne N, Boughman J, Brelsford A, Buerkle CA, Buggs R, Butlin RK, Dieckmann U, Eroukhmanoff F, Grill A, Cahan SH, Hermansen
JS, Hewitt G, Hudson AG, Jiggins C, Jones J, Keller B, Marczewski T, Mallet J, Martinez-Rodriguez P, Möst M, Mullen S, Nichols R, Nolte AW, Parisod C, Pfennig K, Rice AM, Ritchie MG, Seifert B, Smadja CM, Stelkens R, Szymura JM, Väinölä R, Wolf JB, Zinner D (2013) Hybridization and speciation. J Evol Biol 26: 229-246

Burton RS, Barreto FS (2012) A disproportionate role for mtDNA in Dobzhansky-Muller incompatibilities? Mol Ecol 21: 4942-4957

Dobzhansky T (1951) Genetics and the Origin of Species. Columbia University Press, New York

Hewitt GM (1988) Hybrid zones-natural laboratories for evolutionary studies. Trend Ecol Evol 3: 158-167

Hirase S, Ikeda M (2014) Long-term vicariance and post-glacial expansion in the Japanese rocky intertidal goby Chaenogobius annularis. Mar Ecol Prog Ser 499: 217-231

Hirase S, Takeshima H, Nishida M, Iwasaki W (2016) Parallel mitogenome sequencing alleviates random rooting effect in phylogeography. Gen Biol Evol 8: 1267-1278

Hirase S, Ikeda M (2015) Hybrid population of highly divergent groups of the intertidal goby Chaenogobius annularis. J Exp Mar Biol Ecol 473: 121-128.

Kokita T, Nohara K (2011) Phylogeography and historical demography of the anadromous fish Leucopsarion petersii in relation to geological history and oceanography around the Japanese Archipelago. Mol Ecol 20: 143-164

Morgan-Richards M and Wallis GP (2003) A comparison of five hybrid zones of the weta Hemideina thoracica (Orthoptera: Anostostomatidae): degree of cytogenetic differentiation fails to predict zone width. Evol 57: 849-861

Nolte AW, Tautz D (2010) Understanding the onset of hybrid speciation. Trend Genet 26: 54-58

Schumer M, Rosenthal GG, Andolfatto P (2014) How common is homoploid hybrid speciation? Evol 68: 1553-1560

\section{A short review of morphological studies on fishes in Japan}

\section{Masanori Nakae}

\section{National Museum of Nature and Science, Tsukuba, Ibaraki 305-0005, Japan. \\ E-mail: nakae@kahaku.go.jp}

Morphology is a branch of biology that is based on studying the form and structure of the organs of organisms, from which important information can be gained. Because morphological studies have generally provided important fundamental data for various studies, including, for example, those on organ function, age estimation and taxonomy, fish morphology has gained prominence within ichthyology.

However, observational methods, purposes, and comparative popularity of fish morphology have changed over time. For example, a simplified analysis of papers published in the journals of the Ichthyological Society of Japan (i.e., Japanese Journal of Ichthyology and Ichthyological Research) showed the following trends: 1) many papers based on morphological studies were published from the 1970s to the 1990s (18-29\% of the total published); 2) the proportion of such papers has 
decreased to $7-13 \%$ since $2000 ; 3$ ) external morphology and osteology formed the majority of morphological studies in the $1950 \mathrm{~s}$; 4) studies on histology and microstructure of some organs have comprised the majority of papers since the 1960s; 5) phylogenetic studies based on morphology were very popular up to the 1990s, but have since given way to molecular phylogeny.

Although the advantages of a morphological approach have declined in some research areas, such as phylogenetic studies, morphological studies of fishes can still make a significant impact on ichthyology, due to the introduction of new observational techniques and changing perspectives on the characters observed.

The research group that I belong to has recently studied the lateral line system of many teleosts to re-examine the evolution of the former in fishes, based on neuromast distribution. The research group has also studied the lateral line system of captive-bred and wild individuals of some fishes. Much interesting data has been obtained, leading to many new studies. These lateral line system studies have recently become available due to a new staining method for neuromasts (lateral line system sense organs) and have confirmed the benefits of continuing morphological studies of fishes.

\section{Field ecology of fishes: toward a better understanding of ecosystem linkages mediated by fishes}

\section{Takuya Sato}

\section{Graduate School of Science, Kobe University, Rokkodai, Nada, Kobe 657-8501, Japan. \\ E-mail: tsato@people.kobe-u.ac.jp}

Ecosystems are open system, and allochthonous resources (AR), such as organisms, detritus and nutrients that move across ecosystems, can alter bottom-up and top-down forces of community regulation in recipient ecosystems (Polis et al. 1997). Fishes often alter their foraging behavior, life history and population dynamics, depending on AR. Recently, accumulating evidence has suggested that AR are temporally variable; e.g., timing, duration and magnitude (Richardson and Sato 2015). However, few studies have examined empirically how such temporal attributes are important in driving consumer populations, including fishes.

In this talk, I will first briefly review studies of ecosystem interactions by focusing on fishes. Then, I will introduce our studies that have focused on the effects of temporal attributes of AR on salmonid fishes.

Large-scale monitoring revealed that seasonal emergences of terrestrial arthropods and their nematomorph parasites (Sato et al. 2011) synergistically determined the duration (pulsed vs. prolonged within a season) and seasonal timing (early vs. late in a growing season) of AR from forests to streams. A field experiment then revealed that prolonged-AR allowed larger salmonid fish to effectively monopolize the AR, which resulted in creating a more size-varied population structure, compared with pulsed-AR. In another field experiment, fish exhibited a higher numerical response to AR occurring early in the growing season than late-AR, with timing-dependent life history adoptions and diversity. While global warming is well known to advance peak timing of the growing season, it also leads to longer growing seasons (CaraDonna et al. 2014). Our studies suggest that if AR become advanced and prolonged under climate changes, consumers (such as fishes) may increase in abundance, which would in turn cause stronger trophic cascades in recipient ecosystems.

Recent advances in monitoring tools and/or statistical analyses allow fish ecologists to broaden the spatial and temporal scales of their ecological studies. In closing, I will briefly introduce our recent studies aimed at revealing the importance of amphidromous fish in mediating interactions between riverine and marine ecosystems.

\section{References}

CaraDonna PJ, Iler AM, Inouye DW (2014) Shifts in flowering phenology reshape a subalpine plant community. Proc Natl Acad Sci 111: 4916-4921

Polis G., Anderson WB, Holt RD (1997) Toward an integration of landscape and food web ecology: the dynamics of spatially subsidized food webs. Ann Rev Ecol Systemat 28: 289-316

Richardson JS, Sato T (2015) Resource subsidy flows across freshwater-terrestrial boundaries and influence on processes linking adjacent ecosystems. Ecohydrol 8: 406-415

Sato T, Watanabe K, Kanaiwa M, Niizuma Y, Harada Y, Lafferty KD (2011) Nematomorph parasites drive energy flow through a riparian ecosystem. Ecol 92: 201-207

\section{Behavioral ecology in fishes: areas of interest and next-generation research}

\section{Satoshi Awata}

\section{Graduate School of Science, Osaka City University, Sumiyoshi, Osaka 558-8585, Japan. \\ E-mail: sa-awata@sci.osaka-cu.ac.jp}

Behavioral ecology is a field of study aiming to unravel the mystery of animal behavior, based on the idea that traits such as animal behavior and morphology have undergone natural selection during evolution and have evolved adaptively. Because fishes exhibit extremely diverse ecology 
and behavior, they have much to offer as model animals for the study of reproductive strategies and mutualism from the perspective of behavioral ecology. This presentation includes four topics on reproductive strategies in Tanganyikan cichlids and marine sculpins, and on new insights into goby-shrimp symbiosis.

Field studies on cooperation and conflict among group members of the cooperatively breeding cichlid Julidochromis ornatus in Lake Tanganyika, Africa, revealed that: 1) this fish had variable mating combinations including pairs (monogamy) and a female with two males (cooperative polyandry) within a population; 2) subordinate males, being smaller than dominant males, were genetically unrelated to dominants and frequently joined in reproduction; and 3) sperm competition occurred between polyandrous males, with both males investing in testes larger than in monogamous males. Aquarium experiments showed that polyandrous females may control the paternity of two males, such behavior resulting in increased male parental care. The balance between cooperation and reproductive conflict may maintain the stability of cooperative polyandry.

Studies were also undertaken on the evolution of sperm traits in marine sculpins, host utilization by nine sympatric species of marine sculpins and the evolution of ovipositor size. Comparing the sperm traits of 27 species revealed that copulatory species with female parental or no care had longer faster-moving sperm than non-copulatory and copulatory species with male parental care. Copulatory species have elongated sperm heads, and non-copulatory species have oval sperm heads, indicating that sperm evolution may have been based on reproductive modes and sperm competition. Field and genetic studies revealed that the nine sympatric species appeared to differ in their utilization of host species, such as non-colonial tunicates, sponges and colonial tunicates. In addition, we found that two species, which oviposit in colonial tunicates or sponges, have shorter ovipositors than species that deposit eggs in non-colonial tunicates. These results indicated that the sculpins had species-specific host utilization, and ovipositor size may have evolved based on spawning site differences.

Regarding goby-shrimp symbiosis, the relationship between gobies and shrimps is generally thought to be mutually beneficial, with shrimps providing burrows for gobies as refuges, and gobies warning shrimps of potential predators. Recently, however, aquarium experiments have revealed that gobies provide droppings in their burrows as vital food for their partner shrimps. Furthermore, underwater observations found that the shrimps never fed outside their burrows, but actively excavated sand sediments outside the burrows, thus providing feeding opportunities for the gobies. This discovery was outside the conventional interpretation of goby-shrimp symbiosis, and it became clear for the first time that they had a mutualistic relationship based on feeding each other.

Based on these findings, I discuss the new developments about next-generation research of fish behavioral ecology.

\section{The role of neuropeptides in the regulation of fish fighting behavior}

\section{Nao Kagawa}

\section{Faculty of Science and Engineering, Kindai University, Kowakae, Higashiosaka, Osaka 577-8502, Japan. E-mail: kagawa@life.kindai.ac.jp}

Social behavior is ubiquitous in the Animal Kingdom, and the many behavioral types including fighting, schooling and reproductive behavior are observed. In particular, fighting behavior is important for establishing the social rank of individuals. Since social hierarchy influences the food, habitation, health and reproduction of individuals, it is necessary to understand how animals develop social interactions via fighting behavior, and which mechanisms regulate such behavior. However, little is known about the physiological factors and brain responses which regulate fighting behavior. Recently, many studies have demonstrated that neuropeptides in the brain are associated with social behavior in fishes. Here, I will review the findings regarding which neuropeptides are associated with fighting behavior and social hierarchy in fishes.

It has been well established that two hypothalamic neuropeptides, gonadotropin-releasing hormone (GnRH1) and arginine vasotocin (AVT), are associated with fighting behavior and/or social rank in several fish species, e.g., Oncorhynchus mykiss, Astatotilapia burtoni, Oreochromis mossambicus, Thalassoma bifasciatum, Carassius auratus, Danio rerio and Oryzias latipes. Primary among reproductive hormones via the hypothalamus-pituitary-gonad (HPG) axis, GnRH1 has a key role in stimulating the release of gonadotropins into the bloodstream. For example, among male and female $A$. burtoni reared in a single tank in which males had fought each other continuously for a few weeks, dominant males showed a high expression of GnRH1 in the brain resulting in an active HPG axis, whereas subordinate males had a low expression of GnRH1 with often suppressed reproductive function (Fernald and Maruska 2012). Additionally, males can reversibly switch between dominant and subordinate states, according to changes in their social environment, with such state switching involving remarkable changes in fighting behavior and reproductive physiology. For example, removal of dominant males from a tankheld community with an established social hierarchy, and addition of new males smaller than the subordinate males 
already present, resulted in the latter (subordinate males) ascending in social status. Such ascending males increased their aggressive behavior within minutes of recognizing the social opportunity, but GnRH1 levels in the brain required about thirty minutes for a similar increase. Furthermore, other reproductive physiological changes took up to 1 week to achieve levels similar to those in the initially dominant males. This suggests that changes in brain GnRH1 levels depend upon social rank, although GnRH1 itself does not regulate aggressive behavior in male-male competition.

AVT has multiple roles in regulating various physiological and behavioral events, such as osmoregulation, stress response, male-male competition, and reproduction. In many teleosts, AVT neurons have been identified by soma size as comprising three populations in the POA: gigantocellular nuclei (gPOA), magnocellular nuclei (mPOA) and parvocellular nuclei (pPOA), each thought to have different physiological and behavioral functions (Greenwood et al. 2008; Kagawa 2013). For example, AVT levels in the mPOA and PPOA are involved in osmoregulation and the hormonal stress response via the hypothalamus-pituitary-interrenal axis, respectively. Furthermore, high expressions of AVT in the gPOA and mPOA are seen in dominant males, whereas that in pPOA is seen in subordinate males. Additionally, our recent study of Oryzias latipes demonstrated rapid changes in AVT mRNA expression in each brain region within thirty minutes following social status switching. It has also been reported that AVT treatment increases aggressive behavior in Stegastes leucostictus within 15 min, whereas treatment with AVT-receptor antagonist decreases such behavior (Santangelo and Bass 2006). Considering the above evidence, it is suggested that AVT levels in distinct brain regions are good indicators of social rank in fishes, with AVT regulating fighting behavior and physiological events arising from male-male competition.

In addition to the above neuroendocrinological findings, recent studies have suggested the possibility that a social behavior network (SBN) in the brain is responsible for the regulation of fighting behavior in fishes. The SBN model is proposed for understanding the activation of neural circuits in social behavior. In this presentation, I will describe the possible role of GnRH- and AVT-neurons in the SBN in fishes.

\section{References}

Fernald RD, Maruska KP (2012) Social information changes the brain. Proc Natl Acad Sci 109: 17194-17199

Greenwood AK, Wark AR, Fernald RD, Hofmann HA (2008) Expression of arginine vasotocin in distinct preoptic regions is associated with dominant and subordinate behaviour in an African cichlid fish. Proc R Soc B 275: 2393-2402
Kagawa N (2013) Social rank-dependent expression of arginine vasotocin in distinct preoptic regions in male Oryzias latipes. J Fish Biol 82: 354-363

Santangelo N, Bass AH (2006) New insights into neuropeptide modulation of aggression: field studies of arginine vasotocin in a territorial tropical damselfish. Proc R Soc B 273: 3085-3092

\section{Ontogeny of deep sea demersal fishes}

\section{Munehiro Takami}

\section{School of Marine Science and Technology, Tokai University, Shimizu, Shizuoka 424-8610, Japan. \\ E-mail: mune-takami@hotmail.co.jp}

The study of larval fish taxonomy has progressed greatly since 1980, many atlases and identification guides for different stages being published, such as Ozawa (1986) (western north Pacific), Okiyama (1988) and Okiyama (2014) (waters adjacent to Japan), Oliver and Fortuño (1991) (southeastern Atlantic), Moser (1996) (northeastern Pacific), and Leis and Carson-Ewart (2000) (Indo-Pacific). Accordingly, information on larval stages is almost complete for many taxa, but still poorly known in others, the larvae of a number of taxa having never been collected. The latter category includes deep-sea demersal fishes, such as Alepocephalidae, Macrouridae, Ophidiidae and Liparidae. The paucity of deep-sea demersal fish larvae is the consequence of larval sampling having been conducted mainly in the upper water column to date, whereas nearbottom sampling has been neglected due to many inherent difficulties, e.g., the sampling device either contacting the bottom or detaching far from it. Since 2002, a monthly near-bottom larval sampling program has been conducted on the upper continental slope of Suruga Bay, to clarify the ontogeny of resident deep-sea demersal fishes. During the program, sampling problems have been resolved, including construction of a larval sampling device which can be reliably towed by a small survey vessel $(20 \mathrm{t})$ near bottom (1-8 $\mathrm{m}$ above the seabed) at depths of 97-1,121 $\mathrm{m}$.

A total of 261 larvae and juveniles of demersal fishes, representing 27 species (including 12 unidentified) in 15 genera (12 families), were collected by near-bottom sampling between 2006 and 2009. Of these, Leptoderma lubricum and Leptoderma retropinnum (Alepocephalidae), Coryphaenoides marginatus and Coelorinchus kishinouyei (Macrouridae) and Paraliparis dipterus (Liparidae) were the first larval stage records, enabling clarification of their overall ontogeny. Three distribution patterns, including the water column, were determined as follows: type A, larvae to adults occurring only near bottom, e.g., alepocephalids; type B-1, larvae and early juveniles rising to shallower depths in the water column, late juveniles and 
adults occurring near bottom, e.g., macrourids; type B-2, juveniles and adults collected near bottom, but no larvae collected to date, e.g., synaphobranchids and neoscopelids. The general ontogeny of type A species differed from those of type B-1, being characterized by the acquisition of general adult characters, such as fin-ray numbers and body proportions, during an early developmental stage (late developmental stage in type B-1) and indistinct transformation thereafter (transformation stage apparent). The former spawned a few large-diameter demersal eggs (numerous small-diameter pelagic eggs) and remained near bottom throughout life (rising in the water column during the larval stage). The early acquisition of general adult characters in type $\mathrm{A}$ species, related to advancement of swimming ability, apparently contributes to an improvement in predatory ability, as well as mitigation of predation pressure in the early stages. Adult synaphobranchids and neoscopelids (type B-2) were abundantly collected in Suruga Bay. However, larval and juvenile nurseries of those species are likely to be elsewhere in the vast mesopelagic/bathypelagic zone and are yet to be discovered.

\section{References}

Leis JM, Carson-Ewart BM (2000) The larvae of Indo-Pacific coastal fishes: An identification guide to marine fish larvae. Fauna malesiana, Leiden

Moser HG (1996) The early stages of fishes in the California Current region. CalCOFI Atlas 33, Allen Press, Lawrence

Okiyama M (1988) An atlas of the early stage fishes in Japan. Tokai Univ Press, Tokyo

Okiyama M (2014) An atlas of the early stage fishes in Japan, second edition. Tokai Univ Press, Hadano

Oliver MP, Fortuño JM (1991) Guide to Ichthyoplankton of the Southeast Atlantic (Benguela Current Region). Sci Mar 55: 1-383

Ozawa T (1986) Studies on the oceanic ichthyoplankton in the western North Pacific. Kyushu Univ Press, Fukuoka

\section{Contributions of descriptive research to fish conservation}

\section{Jun Nakajima}

\section{Fukuoka Institute of Health and Environmental Sciences, Dazaifu, Fukuoka 818-0135, Japan. \\ E-mail: oikawamaru@gmail.com}

Biodiversity conservation is currently an important social issue, with ichthyologists having certain responsibilities with regard to conservation of fishes. Descriptive research, taxonomy and population ecology all contribute directly to such conservation. In the Red List 2018 (Ministry of the Environment 2018), 252 fish taxa are listed, 35 of which have been newly described since 2000 . While it may be said that taxonomic studies are reflected in the conservation strategy, there remain 33 undescribed/undecided species on the list requiring urgent taxonomic consideration. However, an understanding of life histories based on population ecology is also indispensable for promoting conservation measures. For example, species that move considerably during growth or utilize a special habitat for egg laying may not be protected if only a part of their overall habitat requirement is protected. For species whose life history has been clarified, for example Acheilognathus longipinnis or Parabotia curtus, conservation has been proceeding smoothly (Abe and Iwata 2007; Ogawa 2008). However, there remain many species whose life history has been completely unknown. Recent developments in phylogeography are also important for conservation, with research in this field contributing not only to evolutionary aspects but also to the discovery of unknown genetic clades or concealed species. The reality of descriptive research is such that most is unlikely to be of "high impact", which is disadvantageous owing to recent performance-based trends in research. Nevertheless, the value of descriptive research in conservation is undoubted and must continue to be encouraged and valued. The concluding part is repetitive and has been deleted as such. How is my alternative suggestion, which I think is in keeping with the author's intentions?

\section{References}

Abe T, Iwata A (2007) Ayumodoki (Leptobotia curta), conservation of reproductive areas as the crux of their existence. Japan J Ichthyol 54: 234-238

Ministry of the Environment (2018) Red list 2018. https://www.env. go.jp/press/files/jp/109278.pdf. Accessed 31 July 2018

Ogawa R (2008) Acheilognathus longipinnis: a symbol fish of flood plains with natural hydrometeorological environments. Japan J Ichthyol 54: 144-148 